\title{
Estudo comparativo entre os sincrânios de Otaria byronia e Arctocephalus australis (Pinnipedia, Otariidae)
}

\author{
Daniela Sanfelice \& Jorge Ferigolo
}

Museu de Ciências Naturais, Fundação Zoobotânica do Rio Grande do Sul. Av. Salvador França, 1427, 90690-000 Porto Alegre, RS. (daniela.sanfelice@fzb.rs.gov.br; jorge.ferigolo@fzb.rs.gov.br)

\begin{abstract}
Comparative study between the syncranium of Otaria byronia and Arctocephalus australis (Pinnipedia, Otariidae). A high degree of anatomical variability in many structures of Otaria byronia (Blainville, 1820) and Arctocephalus australis (Zimmerman, 1783) was observed, which should yield serious implications to the systematics of Otariidae. The main differences observed between the two species were: the breadth of the rostrum, the exposure (or not) of the ethmoid in the orbit, the palatine/pterygoid vacuity, the extension of the maxilla, the concaveness and shape of the palate, the size/shape of the orbit/supra-orbital process, the height/shape of the zygomatic arch, the shape of the hamulus pterygoideus, the size of processes and crests, the proportions of the sphenoid and of neurocranium, the occurrence or not of the vidian and transverse canals, the relieves of the cranial fossae, and the size of secondary angular process. While some differences (ethmoid) are rather unusual between contemporary species belonging to the same family, many others are of allometric nature. Some differences are peramorfic: skull size, palate size and crests size (hypermorphic in $O$. byronia). Others caracters are pedomorphic in this species: incisive foramen, maxille process of the frontal and vidian channels. The main differences between males and females of O. byronia, and similitarities between de males of this species and A. australis are related to developmental modification in rate or in the timing too. Some characters usually used in the group's systematics were not corroborated, mostly those related to the naso-labialis fossa; zygomatic-temporal suture; internal acoustic meatus and entotimpanic.
\end{abstract}

KEYWORDS. Syncranium, anatomy, osteology, South American sea lion, South American fur seal.

RESUMO. Observou-se grande variabilidade anatômica no sincrânio de Otaria byronia (Blainville, 1820) e de Arctocephalus australis (Zimmerman, 1783), com correspondentes implicações na sistemática dos Otariidae. As principais diferenças observadas entre as duas espécies foram a largura do rostro, exposição (ou não) do etmóide na órbita, vacuidade palatino/pterigóide, extensão do maxilar, concavidade e forma do palato, tamanho/forma da órbita/processo supra-orbital, altura/forma do palato, tamanho/forma da órbita/ processo supra-orbital, altura/forma do arco zigomático, forma do hâmulo pterigóide, tamanho de processos e cristas em geral, esfenóide e neurocrânio; presença ou não do canal vidiano e transverso; forma do pétreo e proporções do processo angular secundário. Enquanto algumas diferenças (etmóide) são bastante incomuns entre espécies contemporâneas pertencentes à mesma família, muitas outras são de natureza alométrica. Algumas diferenças são peramórficas: tamanho do crânio, do palato e das cristas (hipermórficos em $O$. byronia). Outros caracteres são pedomórficos em $O$. byronia: forame incisivo, processo maxilar do frontal e canais vidianos. As principais diferenças entre machos e fêmeas de O. byronia, e similiraridades entre os machos desta espécie e A. australis estão relacionadas a modificações no tempo/taxa de desenvolvimento. Alguns caracteres usualmente empregados na sistemática do grupo não foram corroborados, principalmente referentes à fossa naso-labialis, sutura jugo-temporal, meato acústico interno, entotimpânico e extensão do pétreo.

PALAVRAS-CHAVE. Sincrânio, anatomia, osteologia, leão-marinho-do-sul, lobo-marinho-do-sul.

Atualmente os Otariidae compreendem sete gêneros, a saber: Arctocephalus (Geoffroy Saint-Hylaire \& Cuvier, 1826), Callorhinus (Gray, 1859), Eumetopias (Gill, 1866), Neophoca (Gray, 1866), Otaria (Péron, 1816), Phocartos (Petters, 1866) e Zalophus (Gill, 1866). Apenas o gênero Arctocephalus não é monoespecífico, compreendendo oito espécies, das quais sete estão distribuídas pelos oceanos do Hemisfério Sul e uma na costa pacífica da América do Norte. Três espécies ocorrem no Brasil: Arctocephalus australis (Zimmerman, 1783), A. tropicalis (Gray, 1872) e A. gazella (Peters, 1875). A monofilia da família Otariidae é geralmente aceita (BERTA, 1991), mas a validade das subfamílias Arctocephalinae e Otariinae é ainda objeto de controvérsia (BERTA \& WYSS, 1994; BRUNNER, 2004; BERTA et al., 2006).

As espécies recentes necessitam maior atenção, sobretudo no que concerne àquelas ocorrentes no litoral do Rio Grande do Sul, onde a maioria dos indivíduos são machos subadultos ou adultos e não há colônias reprodutivas (RosAs et al., 1994). A maior proximidade ao estoque ancestral de Arctocephalus australis confere à presente comparação especial interesse, já que os leões- marinhos teriam derivado dos lobos-marinhos há 2 ou 3 milhões de anos aproximadamente (TEDFORD, 1976).

Neste contexto, objetivou-se: (1) contribuir para um melhor conhecimento sobre a osteologia do sincrânio de Otaria byronia e Arctocephalus australis, ampliando assim os dados acerca dos otarídeos que ocorrem no litoral rio-grandense e iniciando uma comparação entre representantes das subfamílias "Arctocephalinae" e Otariinae; (2) fornecer dados que contribuam para futuros estudos de cunho evolutivo e filogenético sobre os Pinnipedia; (3) fornecer subsídios para uma melhor compreensão do material fóssil, contribuindo para o futuro entendimento das relações ancestral-descendente, em função do contex to controverso em que se encontram as pesquisas sobre a origem e as relações genealógicas dos Pinnipedia e (4) fornecer dados para aplicação no reconhecimento de material arqueológico de pinipédios.

\section{MATERIAL E MÉTODOS}

Descreve-se $O$. byronia e as diferenças de $A$. australis, comparativamente a este. O material utilizado 
consistiu de 68 sincrânios (23 de $O$. byronia; 45 de $A$. australis) pertencentes às coleções de mastozoologia das seguintes instituições: Museu de Ciências Naturais da Fundação Zoobotânica do Rio Grande do Sul; Laboratório de Mamíferos Aquáticos da Universidade Federal de Santa Catarina; Museu de Zoologia das Faculdades de Ciências da Saúde, Universidade do Vale do Rio dos Sinos.

Foram utilizados espécimes adultos com o comprimento do crânio (CCB) $\geq 30 \mathrm{~cm}$ ( (’) e $25 \mathrm{~cm}$ (६). Também foram incluídos na amostra os espécimes subadultos MCN 2612 (क; $\mathrm{CCB}=28,50$; idade sutural (IS)=17) e MCN 2691 ( $;$; CCB=25,80; IS=17). Outros espécimens juvenis e subadultos foram empregados para a análise de algumas suturas e para a determinação da idade cronológica (e. g. MCN 2618). As comparações entre as espécies foram feitas entre representantes de mesmo sexo.

As faixas etárias foram estimadas de acordo com SiverTSEN (1954; suturas cranianas) e SimõES-Lopes et al. (1995). Para determinação da idade cronológica, os caninos superiores foram bi-seccionados longitudinalmente com serra circular diamantada, polidos com lixas d'água de diferentes granulometrias $(400,500,1000$ e 2000) e descalcificados em uma solução de ácido fórmico a 5\%. Na seqüência, as seções foram lavadas em água corrente e secas à temperatura ambiente. Após, foram observadas em microscópio estereoscópio para contagem dos grupos de camadas de crescimento seguindo Laws (1962) e SCHIAVINI et al. (1992). Calculou-se a correlação entre as idades suturais (SIVERTSEN, 1954) e a idade cronológica (LAWS, 1962; Schiavini, 1992) para ambas as espécies (Rosas et al., 1993) e estas foram posteriormente comparadas através do teste t de Student.

Os espécimes MCN 2459, 2501 e 2729 foram seccionados parassagitalmente com uma serra manual para análise das estruturas internas e do plano sagital (e. g. vômer, mesetmóide, turbinais).

Os acrônimos referentes aos dentes são I= incisivo, $\mathrm{C}=$ canino, $\mathrm{PC}=$ pós-canino. $\mathrm{O}$ número que acompanha cada acrônimo identifica o número do dente dentro de sua categoria. A barra inclinada posicionada entre o acrônimo e o número indica que se trata de um dente do crânio e colocada após o número indica que se trata de um dente da mandíbula.

Material examinado. Arctocephalus australis. BRASIL, Santa Catarina: Praia da Armação, Florianópolis, o', 19.VIII.1988, S. Althoff col. (UFSC 1063); Caeira da Barra do Sul, Florianópolis, \&, 12.VII.1994, M. Becker col. (UFSC 1133); Barra Velha, ơ, 19.VIII.1996, IBAMA col. (UFSC1228); Rio Grande do Sul: Litoral riograndense, \&, 04.IX.1990, V. Petry col. (UNISINOS 106); Litoral norte, entre Tramandaí e Mostardas, $\checkmark$, 08.X.1991, GEMARS cols. (UFSC 1135); Litoral Norte, 3。', 03.IX.1993, GEMARS cols. (UFSC $1142,1143,1149$ ); 50, 16.X.1993, GEMARS cols. (UFSC 1154, 1156, 1157, 1158 1159); $\vec{\sigma}, 17.10 .1993$, GEMARS cols. (UFSC 1160); $\vec{\sigma}$ 06.XI.1993, GEMARS cols. (UFSC 1163); 3\%, 19.VIII.1996, GEMARS cols. (UFSC 1166, 1169, 1170); Pinhal, ơ, 13.X.1997, V. Petry col. (UNISINOS 170); Santa Vitória do Palmar, đ’, E. Martino col. (MCN 1021); 2ð, \&, IX.1990, J. Ferigolo col. (MCN 2461, 2522, 2523); f, 17.IX.1994, C. Drehmer col. (MCN 2614); ๑, 18.IX.1995, C. Drehmer col. (MCN 2699); Cidreira, 20, 22.VIII.1992, C. Drehmer col. (MCN 2495, 2508); \&, 23.VIII.1992, C. Drehmer col. (MCN 2509); Mostardas, 30’, 22.VIII.1992, C. Drehmer col. (MCN 2497, 2498, 2501); §’, 19.IX.1994, C. Drehmer col. (MCN 2645), f, 09.VI.1989, M.
Strieder col. (UNISINOS 96), 01.XI.1990, M. Sander col. (UNISINOS 101); đ', 2థ, 13.X.1997, V. Petry col. (UNISINOS 157, 163, 164); Cassino, \&, V.1998, E. Borsato col. (MCN 2833); Rio Grande, đ', 16.IX.1994, C. Drehmer col. (MCN 2600); đ', 1988, Clódio col. (MCN 2706); São José do Norte, 2హ', 18.IX.1994, C. Drehmer col. (MCN 2627, 2630); 20', 17.IX.1995, C. Drehmer col. (MCN 2688, 2689); Palmares do Sul, 20', 19.IX.1994, C. Drehmer col. (MCN 2649, 2650); Tavares, o', 16.IX.1995, C. Drehmer col. (MCN 2685); UNISINOS, 157 , 163, 164, 170; URuguaI, Depto. Rocha: Cabo Polônio, ơ, XI.1985, P. C. Simões-Lopes col. (UFSC 1057).

Otaria byronia. BRASIL, Rio Grande do Sul: Litoral norte, entre Tramandaí e Mostardas, O', 04.X.1991, GEMARS cols. (UFSC 1134), ơ, 16.VIII.1991, GEMARS cols. (UFSC 1140); ๙ँ, 36.IX.1993 (UFSC 1152); ఠ, 17.X.1993, GEMARS cols. (UFSC 1162); 2ॐ, 19. XII. 1993, 2ॐ GEMARS (UFSC 1168, 1171); 12.X.1997, Santa Vitória do Palmar, 3ठ' IX.1990, J. Ferigolo col. (MCN 2459, 2460, 2462), $\widetilde{\sigma}$, sexo indeterminado, 17.IX.1994, C. Drehmer col. (MCN 2612, 2618), 20, 29, 18.IX.1995, C. Drehmer col. (MCN 2697, 2700, 2701, 2703); Mostardas, ơ, 22.VIII.1992, C. Drehmer col. (MCN 2505); Rio Grande, 30;, \&, 16.IX.1994, C. Drehmer col. (MCN 2601-2604); ఫै, 16.IX.1994, C. Drehmer col. (MCN 2624); ఫै, VII.1997, E. Borsato col. (MCN 2807); São José de Norte, ऊ, 18.IX.1994, C. Drehmer col. (MCN 2629); đ, \&, 17.IX.1995, C. Drehmer col. (MCN 2691, 2696); శึ, VII.1998, E. Borsato col. (MCN 2832); 04.IX.1990, V. Petry col. (UNISINOS 107).

\section{RESULTADOS}

Comparação quanto a aspectos gerais. O rostro de $O$. byronia é curto e marcadamente largo, particularmente na região dos caninos (Fig. 1). O palato ósseo é largo e muito longo comparativamente aos demais gêneros de Otariidae. Apresenta-se acentuadamente côncavo láterolateralmente, sobretudo nos machos. A órbita é grande, arredondada e geralmente mais alta do que larga, sendo proporcionalmente maior nas fêmeas. A vacuidade orbital é de grandes proporções. O arco zigomático é algo sinuoso e oblíquo médio-lateralmente. A porção craniana propriamente dita é aproximadamente trapezoidal, particularmente nos machos. A fossa temporal está bem definida (Figs. 1 e 4). A crista nucal dorsal determina para o occiput uma forma quadrangular nos machos $\mathrm{e}$ dorsalmente mais arredondada nas fêmeas (Figs. 1, 2 e 5).

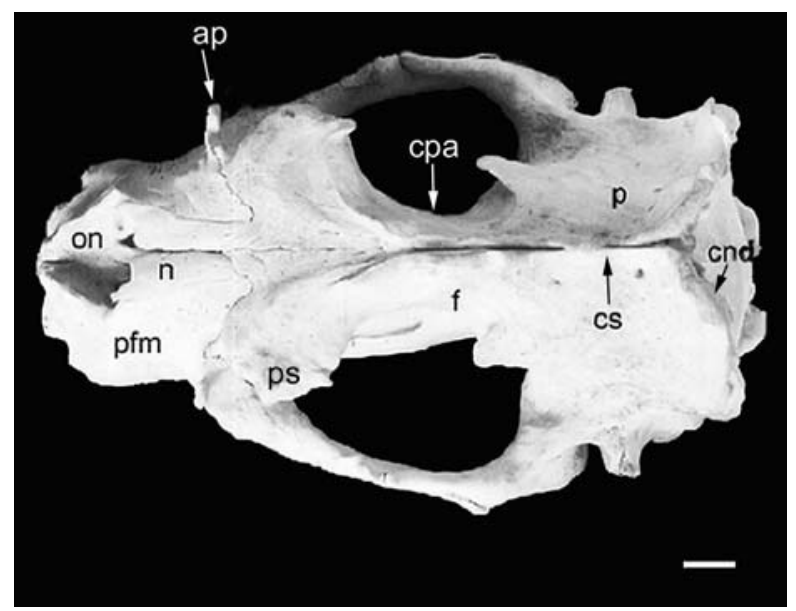

Fig. 1. Otaria byronia (Blainville, 1820) (MCN 2629), macho adulto. Vista dorsal do crânio. Barra, $2 \mathrm{~cm}$ (ap, apófise pré-orbital; cnd, crista nucal dorsal; cpa, constrição pós-orbital; cs, cristas sagitais; $f$, frontal; $n$, nasal; on, orifício nasal externo; pfm, processo frontal do maxilar; $\mathrm{p}$, parietal; ps, processo supraorbital). 
Os resultados de determinação das faixas etárias através dos dois métodos empregados foram discordantes em $O$. byronia. Vários espécimes machos desta espécie apresentam a sutura basal completamente fusionada (portanto, adultos segundo SiMÕES-LoPEs et al., 1995), mas não alcançam a idade sutural mínima para um adulto (IS=18) segundo o método de SiVERTSEN (1954).

Comparativamente, o crânio de A. australis é notadamente mais delicado que o de $O$. byronia, no que se resumem as principais diferenças. $\mathrm{O}$ rostro é mais alongado e afilado. $O$ palato é menos côncavo, mais curto e de largura constante. A órbita é proporcionalmente maior, mais larga e menos alta. A constrição pós-orbital é mais retilínea (Fig. 6). A vacuidade orbital possui contornos mais irregulares. $\mathrm{O}$ arco zigomático é mais baixo e mais uniforme nos contornos. A porção craniana propriamente dita é proporcionalmente maior. As cristas cranianas são menos desenvolvidas. O occiput é triangular em função do menor desenvolvimento das cristas sagital e nucal dorsal (Figs. 6, 7, 9 e 10).

Para esta espécie, os métodos de SiMõEs-Lopes et al. (1995) e SiVERTSEN (1954) apresentaram resultados compatíveis/semelhantes.

Comparação detalhada do crânio. A correlação entre a idade sutural e a idade cronológica para $O$. byronia $(\mathrm{r}=0,69)$ e para $A$. australis $(\mathrm{r}=0,94)$ foi significativa em ambas as espécies $(\mathrm{p} \leq 0,05)$ e significantemente diferente entre as espécies (Fig. 15). As principais características de A. australis, muitas das quais o distinguem do crânio de $O$. byronia, são as seguintes: a tuberosidade prémaxilar é mais desenvolvida e afilada, sendo invariavelmente a estrutura mais anterior do crânio. Não há um pequeno processo na margem do orifício nasal externo (tal como ocorre em $O$. byronia). As séries alveolares dos incisivos formam uma linha anteriormente convexa, especialmente nas fêmeas. O alvéolo para o I3/ é menor, oblongo e mais estreito que o correspondente em $O$. byronia. Sua margem anterior é alinhada com as margens dos demais incisivos ou é levemente posterior. O processo alveolar é pouco desenvolvido. A série dos pós-caninos pode ser retilínea ou sinuosa (médioanteriormente convexa e médio-posteriormente côncava). Os alvéolos dos pós-caninos são menos arredondados e sua forma é mais variável (sempre em comparação com aqueles de $O$. byronia). Os alvéolos não são tão

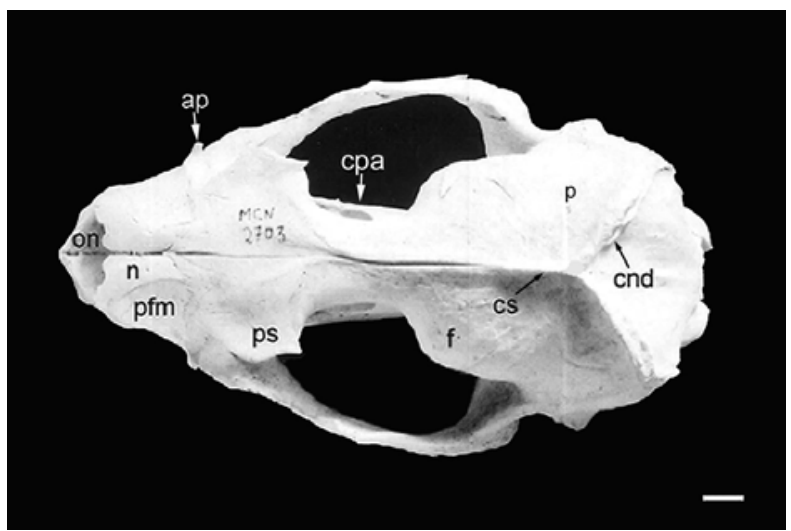

Fig. 2. Otaria byronia (Blainville, 1820) (MCN 2703), fêmea adulta. Vista dorsal do crânio. Barra, $2 \mathrm{~cm}$ (ap, apófise pré-orbital; cnd, crista nucal dorsal; cpa, constrição pós-orbital; cs, cristas sagitais; $\mathrm{f}$, frontal; $\mathrm{n}$, nasal; on, orifício nasal externo; pfm, processo frontal do maxilar; $\mathrm{p}$, parietal; ps, processo supraorbital). profundos e tampouco apresentam inclinação posterior. Os septos interalveolares são mais espessos. Os septos interadiculares são mais constantes, excetuando-se o alvéolo para o $\mathrm{PC} 1 /$. Os dos $\mathrm{PC} 2 /$ e $\mathrm{PC} 3 /$ podem estar indivisos ou apresentarem septos interadiculares incompletos. O alvéolo para o PC4/ pode assemelhar-se ao padrão dos anteriores ou ainda apresentar-se totalmente dividido. Os alvéolos correspondentes aos PC5-6/ apresentam invariavelmente septos interadiculares nos mais diversos graus de desenvolvimento, sendo que no PC6/ podem estar individualizados um ou dois septos. Posteriormente ao PC6/ não há uma lâmina vertical do processo palatino e sim um pequeno prolongamento do maxilar, curto e que não apresenta inclinação látero-medial. Afila-se posteriormente formando uma apófise livre ou um pequeno forame alongado. O processo palatino é mais estreito e a concavidade da face ventral não é acentuada. A apófise pré-orbital possui a base relativamente estreita e baixa e a extremidade dorsal é normalmente mais pontiaguda. A sutura com o nasal varia, estendendo-se entre o processo frontal e a borda lateral do nasal. Todavia, geralmente esta sutura está reduzida a uma porção muito curta, posterior à apófise nasal do prémaxilar. Isto se deve à presença da apófise maxilar do frontal, que contata com a margem lateral do nasal mais

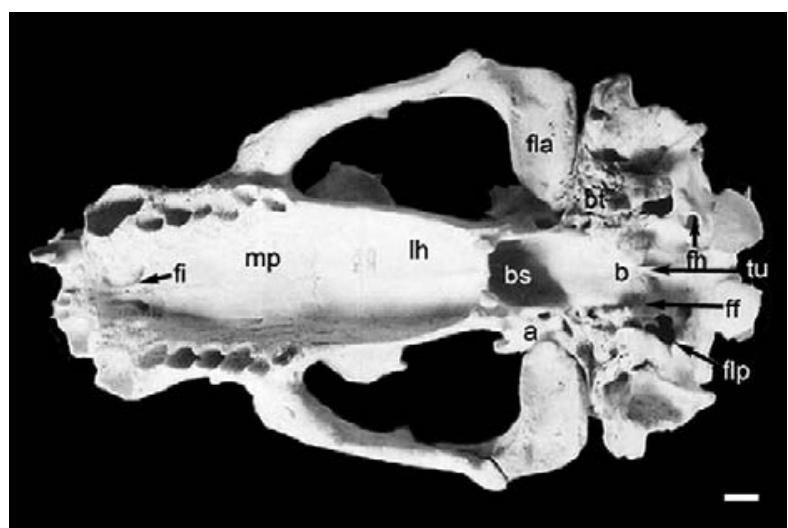

Fig. 3. Otaria byronia (Blainville, 1820) (MCN 2629), macho adulto. Vista ventral do crânio. Barra, $2 \mathrm{~cm}$ (a, alisfenóide; b, basioccipital; bt, bula timpânica; bs, basisfenóide; fi, forame incisivo; ff, fossa faríngea; fh, forame hipoglosso; fla, fossa mandibular; flp, forame lacerado posterior; $\mathrm{lh}$, lâmina horizontal do palatino; mp, processo palatino do maxilar; tu, tubérculo faríngeo).

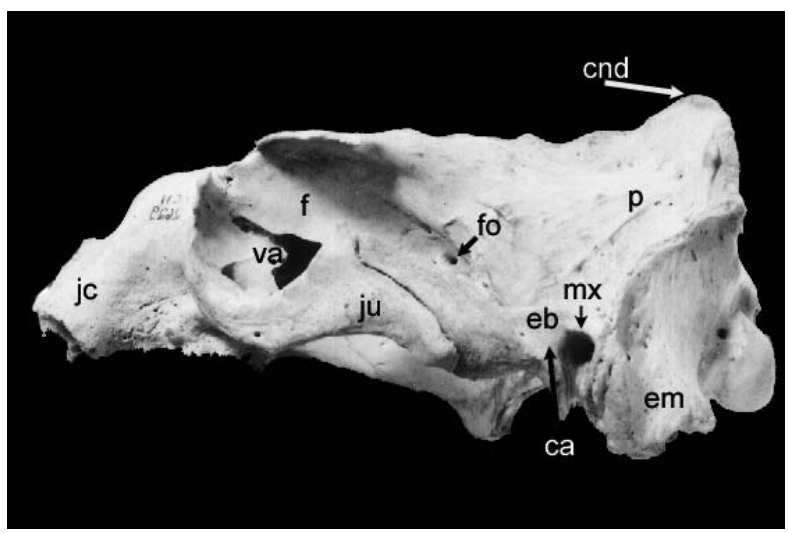

Fig. 4. Otaria byronia (Blainville, 1820) (MCN 2629), macho adulto. Vista lateral direita do crânio. Barra, $2 \mathrm{~cm}$ (ca, crista mastóide anterior; cnd, crista nucal dorsal; eb, esquamosal; em, escama mastóide; f, frontal; fo, forame óptico; jc, jugo alveolar do canino; ju, jugal; mx, meato acústico externo; p, parietal; va, vacuidade orbital). 
posteriormente em uma sutura lisa e retilínea ou ligeiramente curva. Em geral, a sutura com o frontal também difere marcadamente em função da apófise maxilar do frontal. O maxilar contata o frontal na margem médio-posterior em extensão variável, mas a forma da sutura é a de uma linha levemente oblíqua médiolateralmente que se estende até a extremidade mais posterior do processo frontal do maxilar. Tal sutura acompanha a forma posteriormente côncava da borda posterior do processo frontal do maxilar, estendendo-se até as proximidades da apófise pré-orbital. A sutura com o contra-lateral e com o vômer são menos serrilhadas. A sutura com a lâmina horizontal do palatino se inicia mais posteriormente. Pode-se individualizar uma porção láteromedial (anterior) e uma ântero-posterior, mas a sutura também pode apresentar leve concavidade posterior. A sutura ao nível da "apófise pterigóide" é retilínea ânteroposteriormente.

O nasal é mais largo anteriormente, onde sua borda anterior é menos côncava e com uma apófise nasal lateral menor (Fig. 7). A apófise nasal medial é delicada. A sutura internasal freqüentemente é muito serrilhada. Na borda

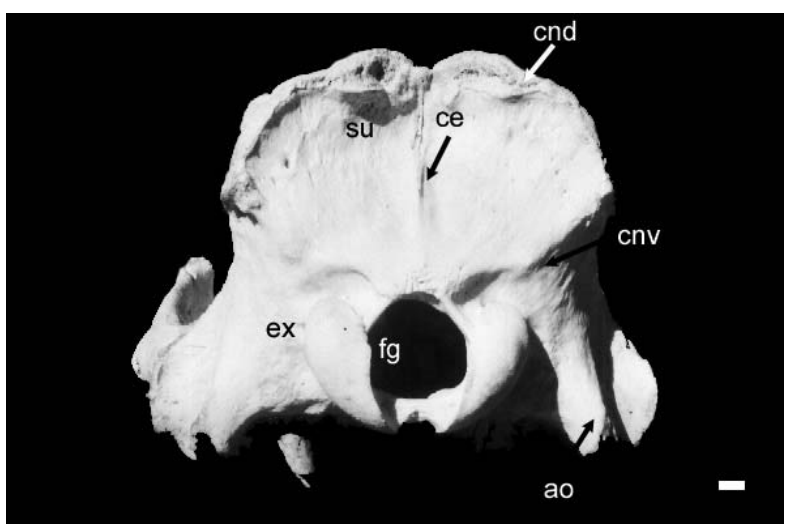

Fig. 5. Otaria byronia (Blainville, 1820) (MCN 2629), macho adulto. Vista posterior do crânio. Barra, $1 \mathrm{~cm}$ (ao, processo paraoccipital; ce, crista occipital externa; cnd, crista nucal dorsal; cnv, crista nucal ventral; ex, exoccipital; fg, forame magno; su, supraoccipital).

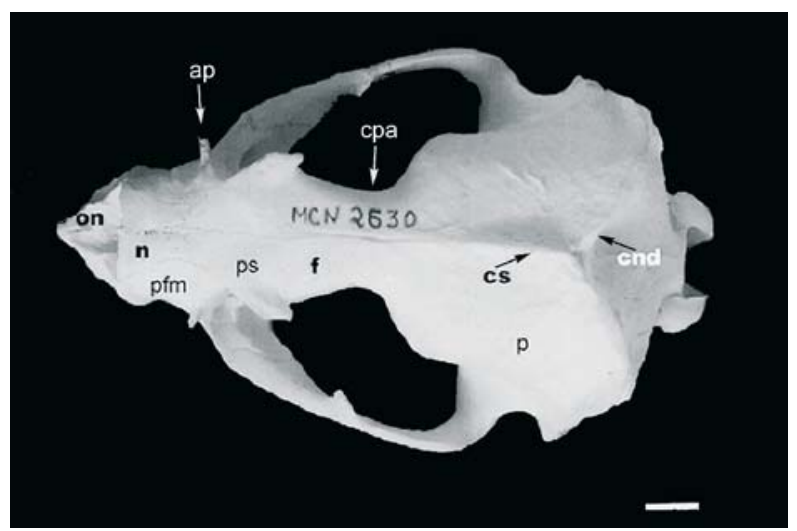

Fig. 6. Arctocephalus australis (Zimmerman, 1783) (MCN 2630), macho adulto. Vista dorsal do crânio. Barra, $2 \mathrm{~cm}$ (ap, apófise pré-orbital; cnd, crista nucal dorsal; cpa, constrição pós-orbital; cs, cristas sagitais; f, frontal; n, nasal; on, orifício nasal externo; pfm, processo frontal do maxilar; p, parietal; ps, processo supraorbital). lateral posteriormente articula-se com a apófise maxilar do frontal. Sua forma é semelhante a um triângulo de ápice posterior cuja forma da base é variável (a borda anterior em "V" de vértice posterior é mais comum entre os jovens, sendo côncava na maioria dos adultos). A face dorsal geralmente só é convexa em jovens.

O jugal é mais longo, mais delicado e mais baixo, não se estendendo tão anteriormente. A face dorsal é menos côncava e sua borda dorso-lateral é mais bem marcada. A face lateral é mais convexa. A borda ventral à órbita é freqüentemente retilínea. O processo pós-orbital é mais posterior, tem a base mais curta e é mais pontiagudo, sendo algo inclinado medialmente. O processo esquamosal estende-se mais posteriormente até o nível da porção média da região craniana propriamente dita.

A lâmina horizontal do palatino é proporcionalmente mais curta e sua face ventral tem concavidade menos acentuada (Fig. 8). A margem anterior situa-se ao nível do PC4/-PC5/. A borda lateral está bem definida, em geral paralela à margem alveolar. A borda posterior tem a forma de um "V" cuja extremidade anterior situa-se ao nível da borda posterior da vacuidade orbital. Posteriormente esta

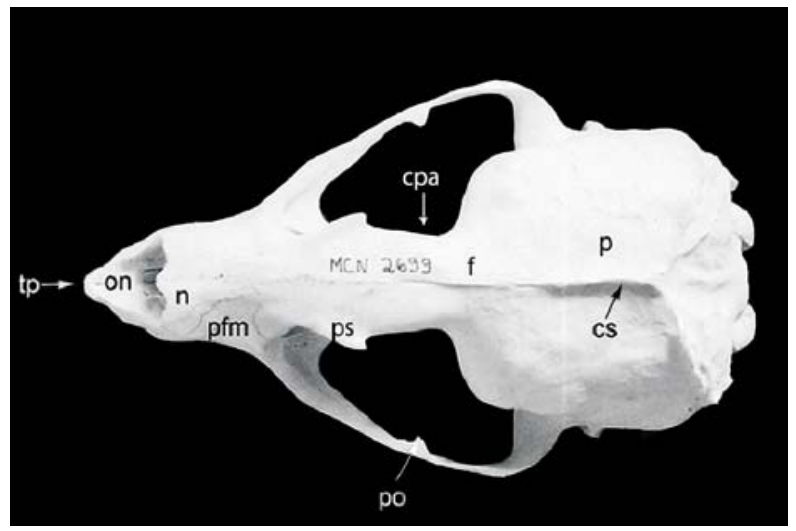

Fig. 7. Arctocephalus australis (Zimmerman, 1783) (MCN 2699), fêmea adulta. Vista dorsal do crânio. Barra, $1 \mathrm{~cm}$ (cpa, constrição pós-orbital; cs, cristas sagitais; $\mathrm{f}$, frontal; $\mathrm{n}$, nasal; on, orifício nasal externo; pfm, processo frontal do maxilar; p, parietal; po, processo pós-orbital; ps, processo supraorbital; tp, tuberosidade pré-maxilar).

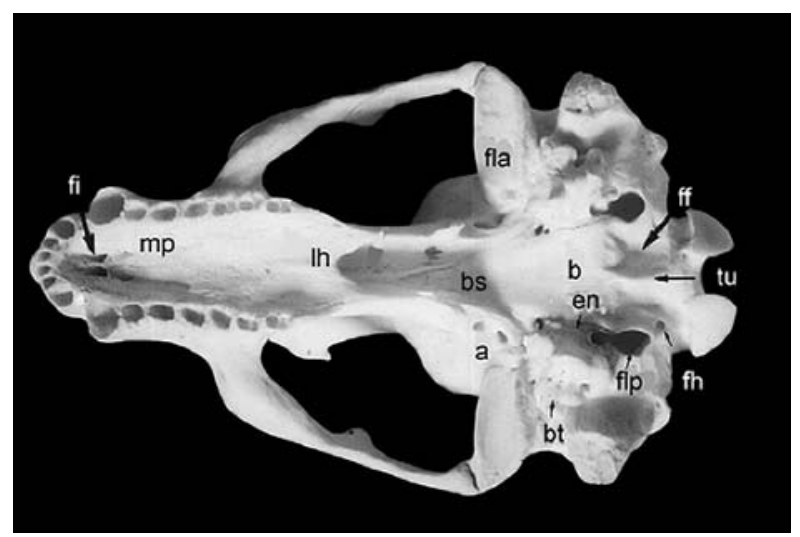

Fig. 8. Arctocephalus australis (Zimmerman, 1783) (MCN 2630), macho adulto. Vista ventral do crânio. Barra, $1 \mathrm{~cm}$ (a, alisfenóide; b, basioccipital; bt, bula timpânica; bs, basisfenóide; fi, forame incisivo; $\mathrm{ff}$, fossa faríngea; fh, forame hipoglosso; fla, fossa mandibular; flp, forame lacerado posterior; lh, lâmina horizontal do palatino; $\mathrm{mp}$, processo palatino do maxilar; tu, tubérculo faríngeo). 
lâmina não se estreita muito. A lâmina vertical é mais baixa e mais convexa dorso-ventralmente. Ela estende-se mais posteriormente que a lâmina horizontal. Sua borda ventral é menor, podendo ser côncava. Não há contato com o frontal. A borda posterior tem a porção dorsal livre, delimitando uma vacuidade (Fig. 9). O processo esfenoidal é razoavelmente bem desenvolvido e mais convexo lateralmente, sendo menos lateral e em continuidade com a lâmina vertical.

As faces do pterigóide são menos uniformes. A lateral é ligeiramente côncava dorso-ventralmente, enquanto que a medial é anteriormente côncava mais dorsalmente e convexa mais ventralmente. A borda anterior é em geral irregular. Dorsal e anteriormente ela é livre, delimitando com a lâmina vertical do palatino uma vacuidade normalmente irregular. Ventralmente à vacuidade esta borda é marcadamente côncava e a seguir convexa. A borda posterior é acentuadamente côncava. A borda dorsal, melhor visível lateralmente também é irregular. $\mathrm{O}$ hâmulo pterigóide situa-se no encontro das bordas ventral e posterior, sendo fortemente inclinado lateralmente e tem forma de uma quilha de ápice posterior, estando no mesmo plano do osso.

A crista frontal externa do frontal geralmente é muito tênue. O processo nasal é sempre a porção mais anterior do frontal. O processo maxilar é estreito, mas bem desenvolvido, o que confere à borda anterior a forma de um "W". A borda anterior é geralmente convexa lateralmente. O processo supra-orbital é menos desenvolvido e seu limite posterior ocasionalmente apresenta uma pequena apófise (Fig. 7). A borda ventral livre é mais curta devido à articulação com a lâmina papirácea do etmóide, que participa no limite dorsal da vacuidade orbital. A constrição pós-orbital é menos marcada. A porção frontal da crista sagital é menos desenvolvida ou ausente (Fig. 7). O processo frontal está ausente ou há somente uma tuberosidade no local. Não há contato com a lâmina vertical do palatino ou com a borda anterior do esquamosal.

Quanto às suturas/margens, o parietal contata o alisfenóide ântero-ventralmente.

O processo zigomático do esquamosal é bastante mais delicado, mais baixo e mais horizontalizado, formando apenas um terço do arco zigomático. A sutura com o jugal é mais longa e mais horizontalizada. A fossa mandibular é mais curta ântero-posteriormente e o processo retroglenóide é menor. O entotimpânico não apresenta projeções ventrais. Os forames do canal da carótida são mais arredondados, e o canal é menos inclinado dorsoventralmente. A escama mastoidea é mais estreita e côncava. O processo mastóide tem forma triangular mais definida, estende-se menos ventralmente e está mais distante da fossa mandibular. O ossículo mastóide é proporcionalmente mais largo e sua face externa é convexa, não estando tão profundamente articulado. No esfenóide, os sulcos relacionados ao canal vidiano não são visíveis na maioria dos casos, o que possivelmente se deve à vacuidade entre o palatino e o pterigóide. Alisfenóide e orbitosfenóide são proporcionalmente maiores e mais regulares. O alisfenóide está mais lateralmente situado. $\mathrm{O}$ basisfenóide é relativamente mais estreito (Fig. 8), mas a porção que se situa entre a lâmina vertical do palatino, a fossa mandibular e o pterigóide é mais larga. O processo pterigóide é mais oblíquo.
Os côndilos apresentam-se menos inclinados látero-medialmente e as fossas condilóides dorsais e ventrais não são muito evidentes. O tubérculo dorsal ao forame magno está reduzido a uma área rugosa. Os tubérculos musculares são menores e de forma mais irregular e o tubérculo faríngeo é menos conspícuo. A metade anterior do basioccipital é mais côncava.

Descrição de acidentes e ossos de regiões específicas do sincrânio de Otaria byronia e comparação com Arctocephalus australis - Coanas. Em O. byronia são altas e de forma quadrangular; e a borda posterior do vômer situa-se muito anteriormente, ao nível da margem anterior da vacuidade orbital (Fig. 3). Em A. australis as coanas são alongadas, têm a margem anterior arredondada e iniciam-se mais anteriormente, além de seu limite ser mais triangular (Fig. 8). A borda posterior da parte sagital do vômer, embora também bastante anterior, situa-se no nível da porção média da vacuidade orbital.

Órbita e arco zigomático. Em $O$. byronia a órbita é limitada anteriormente pelo lacrimal e apófise pré-orbital. O processo supra-orbital forma o teto, e a lâmina descendente a parede medial. Ventralmente ela é formada mais medialmente pelo jugal, até o processo pós-orbital. Posteriormente a órbita está em continuidade com a fenestra temporal. Além do frontal, participam também da parede medial da órbita o lacrimal, pequena porção do maxilo-turbinal, o processo palatino do maxilar e a lâmina vertical do palatino. Na parede medial da órbita situa-se também a maior parte da vacuidade orbital (Fig. 4). O arco zigomático é sinuoso lateralmente. Até o processo pósorbital, o arco zigomático é baixo, sendo sua face lateral muito baixa. A partir do processo pós-orbital, a margem dorsal do processo zigomático do esquamosal inclina-se ventralmente em ângulo quase agudo até um nível dorsal à fossa mandibular, depois ascendendo pela crista suprameatal até atingir a crista nucal dorsal (Fig. 4). Ântero-dorsalmente possui uma concavidade profunda, na face dorsal do jugal, margem ventral da órbita e uma convexidade variável tanto na face lateral quanto na borda ventral. A borda ventral é anteriormente convexa, sendo côncava em sua metade posterior. Posteriormente situa-se a fossa mandibular. Em A. australis, a porção anterior do arco zigomático é mais convexa, o processo pós-orbital mais pontiagudo e a margem ântero-ventral da órbita aguda e não arredondada.

Vacuidade orbital. Em O. byronia, participam de seus limites: frontal e órbito-esfenóide (dorsalmente); lacrimal e pequena porção do maxilo-turbinal (anteriormente); processo palatino do maxilar e lâmina horizontal do palatino (ventralmente) e lâmina vertical do palatino (póstero-ventralmente). Em A. australis a lâmina papirácea do etmóide forma parte da borda dorsoposterior da vacuidade orbital.

Fossa temporal e cristas cranianas. Em O. byronia a superfície da fossa apresenta inúmeras cristas e sulcos, especialmente mais anteriormente. Sua superfície é marcadamente convexa dorso-ventralmente, com porções marginais dorsal e posterior côncavas devido às cristas cranianas. Tal fossa situa-se sobre o frontal, parietal e uma pequena parte do esquamosal. Seus limites anteriores são imprecisos. Limita-se dorsalmente pela crista sagital e posteriormente pela crista nucal dorsal, ventralmente continuando-se pela fossa triangular sobre a base do processo zigomático do esquamosal. A crista sagital 
estende-se ântero-posteriormente lateralmente às suturas interfrontal e interparietal, a partir das cristas frontais externas. Sua altura aumenta progressivamente e em sentido posterior. A crista nucal dorsal (Figs. 1 e 4) é muito larga, apresentando com freqüência irregularidades e pequenas tuberosidades. Sobre o plano sagital localizase o ponto mais alto do crânio e quando observada dorsalmente apresenta a forma de um "V" de ápice anterior, localizado sobre a sutura interparietal. Ao nível da crista nucal ventral a crista nucal dorsal flexiona-se anteriormente, em direção ao meato acústico externo (Fig. $5)$. Dorsalmente ao processo mastóide a crista divide-se em duas cristas menores, anterior e posterior. Muitas vezes a crista sagital apresenta-se bastante sinuosa nos machos. Nas fêmeas, as cristas nucal dorsal e a "sagital" são notavelmente menores, podendo estar fusionadas em uma crista única mais posteriormente (Fig. 2). Em A. australis, devido às menores dimensões das cristas (Figs. 6 e 9), a fossa temporal é menos côncava nas margens. Sua área é proporcionalmente maior, mas as cristas e sulcos são mais discretos. A crista "sagital" é a porção mais dorsal do crânio na grande maioria dos espécimes, mas não se estende tão anteriormente quanto em $O$. byronia. A crista nucal dorsal flexiona-se anteriormente menos marcadamente. A crista frontal externa é muito tênue, como pode também ser a "sagital", mais anteriormente.

Fissura esfenoidal. Em ambos, é oblíqua, estreita e alongada dorso-ventralmente, situada ventroposteriormente ao forame óptico e dorso-medial ao canal do alisfenóide. Seus limites são formados pelo alisfenóide, exceto por pequena extensão do limite ântero-dorsal, formada pelo orbitosfenóide.

Canal vidiano. Em $O$. byronia este canal corre ântero-posteriormente entre a lâmina vertical do palatino e o alisfenóide, lateralmente ao vômer. A abertura anterior muitas vezes está obliterada nos adultos. A abertura posterior do canal vidiano situa-se entre a abertura posterior do canal do alisfenóide e a abertura anterior do canal da carótida, na base do processo pterigóide do basisfenóide. Em A. australis o canal é visualizado apenas em alguns poucos espécimes.

Basicrânio. Em O. byronia o forame lacerado médio é em geral circular, podendo ser ovóide. Situa-se na porção mais anterior do entotimpânico, que em alguns espécimes o engloba completamente através de uma projeção anelar. $\mathrm{O}$ alisfenóide pode também participar do limite lateral. $\mathrm{O}$ processo paraoccipital projeta-se látero-posteriormente e é formado pelo exoccipital (porção posterior) e escama mastóide (porção anterior) (Fig. 5). Em vista posterior, sua extremidade ventral assemelha-se a um triângulo de ápice dorsal. A crista paraoccipital é convexa lateralmente e estende-se ântero-posteriormente e látero-medialmente desde a crista mastóide posterior até o processo paraoccipital. O forame lacerado posterior é a maior abertura do basicrânio (Fig. 3). Sua forma geralmente corresponde a um semicírculo, mas suas bordas podem ser irregulares. Ântero-medialmente é limitado pelo basioccipital e ântero-lateralmente pelo entotimpânico. Uma pequena porção lateral é formada pela escama mastoidea. Os limites posteriores são formados pelo exoccipital (medialmente) e pelo entotimpânico (lateralmente). Eventualmente o exoccipital pode estender-se mais anteriormente de modo que a porção basioccipital não chega a participar das bordas deste forame. Em A. australis o processo paraoccipital é pequeno, apresentando-se como uma crista dirigida póstero-ventalmente, unida ao processo mastóide pela crista paraoccipital curva, dirigida ventralmente (Fig. 10). $\mathrm{O}$ forame lacerado posterior é mais alongado. A crista paraoccipital é menor, como as cristas em geral, sendo também menos verticalizada e côncava ventralmente.

Cavidade nasal e fossa craniana anterior. A forma do orifício nasal externo de $O$. byronia é cordiforme ou triangular (Fig. 1), conforme a margem anterior dos nasais. Ântero-ventralmente ele é limitado pelo corpo dos prémaxilares e lateralmente pelos processos nasais dos prémaxilares. No assoalho deste orifício observam-se as apófises palatinas dos pré-maxilares, que se estendem até sua sutura com as lâminas laterais do vômer, através de lâminas muito delgadas. Tal sutura é sinuosa, as lâminas do vômer se superpondo à dos pré-maxilares, sem a elas fusionarem-se. O limite ventral do mesetmóide apresenta uma vacuidade cônica que se interpõe entre as lâminas laterais do vômer.

Os naso-turbinais apresentam-se como uma lâmina extremamente fina e alongada ântero-posteriormente. Sua face dorsal é convexa e inclinada médio-lateralmente. $\mathrm{O}$ osso é mais delicado medialmente e mais espesso lateralmente. Ele se estende desde o limite anterior do maxilo-turbinal até o etmoturbinal I, ao qual pode fusionarse póstero-lateralmente. Medialmente ele se aproxima do mesetmóide, mas não chega a contactá-lo.

Os maxilo-turbinais são extremamente complexos. Anteriormente a crista maxilo-turbinal fusiona-se ao maxilar e posteriormente participa na vacuidade orbital. Em vista parassagital o osso tem forma globosa, situado entre o ádito da cavidade nasal anteriormente e os etmoturbinais posteriormente, além de circundar o nasoturbinal ventralmente. Partindo da crista maxilo-turbinal, o osso apresenta uma lâmina principal dirigida ventral e medialmente. Desta lâmina partem duas lâminas secundárias no sentido medial e três ou quatro lateralmente. A partir das cristas secundárias partem cristas terciárias dorsal e ventralmente, cada vez mais delgadas. Uma pequena porção da crista maxilo-turbinal está exposta no limite anterior da vacuidade orbital, onde parece participar na parede medial da órbita.

$\mathrm{O}$ vômer é muito longo e estende-se desde a sutura com os pré-maxilares até o basisfenóide. Ventralmente estende-se até a lâmina horizontal do palatino. A parte sagital constitui-se de duas lâminas laterais que se fusionam. Estas se unem ântero-ventralmente para constituir o sulco do septo nasal, onde se sutura e depois se fusiona ao mesetmóide. Nas faces laterais destas lâminas observa-se um conspícuo sulco que se estende obliquamente até o labirinto etmoidal. A borda ventral anteriormente é sutural com o pré-maxilar, estendendose posteriormente e suturando-se a este ventralmente ao contato pré-esfenóide/basisfenóide. Posteriormente, aproximadamente ao nível do limite posterior do maxiloturbinal, a borda ventral é livre e marcadamente côncava. As lâminas horizontais são largas e de contornos levemente irregulares. Suturam-se dorsal e lateralmente à lâmina horizontal dos palatinos e/ou à margem ventromedial dos órbito-esfenóides. Posteriormente podem alcançar o basisfenóide através das apófises vomerianas, triangulares, que se unem sagitalmente formando uma incisura sob o pré-esfenóide e basisfenóide. Geralmente estas apófises conferem à borda posterior a forma de um 
"V" de vértice anterior. Mais anteriormente, a borda ventral pode ser visualizada através da vacuidade orbital.

A borda anterior do mesetmóide é livre. Ânterodorsalmente articula-se com a borda medial do nasal e o processo nasal do frontal. Sua borda ventral contata e fusiona precocemente com o vômer. A face lateral do mesetmóide apresenta inúmeros sulcos curvilíneos, mais numerosos posteriormente e relacionados aos filetes no nervo olfativo. Os etmoturbinais são proeminentes. $\mathrm{O}$ labirinto etmoidal é mais largo anteriormente, estreitandose posteriormente. Entretanto, não é tão estreito quanto à lâmina crivosa (parte dele está recoberto pelo frontal). A lâmina papirácea apresenta-se irregular e extremamente fina. Ela se fusiona ao frontal e a porção mais anterior do alisfenóide.

A lâmina crivosa (face endocraniana) é alta, estreita e muito côncava, com inúmeros forames cribiformes com tamanho entre 0,5 e 2,0 $\mathrm{mm}$. Ventro-lateralmente a ela está a abertura interna do forame etmoidal, bastante conspícua. A apófise crista galli é muito alta, cobrindo toda a extensão dorso-ventral da lâmina crivosa. Posteriormente, ao nível do jugo esfenoidal a apófise fusiona-se à região préesfenoidal, mas não ao frontal, dorsalmente. A lâmina crivosa se sutura dorsal e lateralmente ao frontal, e posteriormente à região pré-esfenoidal, mas só se fusiona a esta última.

Em A. australis, a lâmina principal do vômer é horizontalizada da qual partem 3-4 lâminas secundárias dorsalmente e 3-4 ventralmente, posteriormente e lateralmente as lâminas confluem em uma lâmina vertical comum (que frequientemente está exposta na vacuidade orbital). O sulco lateral nas lâminas verticais é menos pronunciado. As lâminas horizontais são bastante mais estreitas. As apófises vomerianas são extremamente finas e alongadas, conferindo à incisura a forma de um triângulo mais estreito e mais longo do que aquele de $O$. byronia. O mesetmóide parece menos ossificado na extremidade ântero-dorsal, e possivelmente tem menor número de sulcos laterais. A lâmina crivosa é mais larga anteriormente e estreita-se posteriormente. Os forames são maiores e em menor número. A apófise crista galli apresenta um sulco verticalizado em sua face lateral, é mais espessa e mais alta e não está fusionada à região pré-esfenoidal. Esta apófise apresenta-se como uma lâmina oblíqua dorso-ventralmente, cuja borda posterior é aproximadamente retilínea. A sutura com o vômer é mais variável em extensão, podendo ser bastante curta.

Teto craniano e fossas cranianas média e posterior. Em $O$. byronia apenas as suturas do frontal com o etmóide, do orbitosfenóide/região pré-esfenoidal e deste com o basisfenóide, e a do pétreo com ossos adjacentes (e. g. esfenóide) não estão fusionadas. A sutura frontoparietal internamente é extremamente imbricada, sobretudo ao nível da crista "sagital". No teto e fossa craniana média há muitos sulcos e cristas correspondentes aos giros e sulcos cerebrais, além dos sulcos para os tênues vasos meningeus, como o da artéria meningéia média. Este sulco situa-se látero-dorsalmente ao forame oval. Estende-se sobre o alisfenóide por curta extensão. Ramifica-se muito dorsalmente, mas seu ramo principal estende-se obliquamente ântero-ventralmente/pósterodorsalmente. O processo tentório, bem ossificado, é uma espessa lâmina marcadamente convexa dorsalmente, perpendicular à foice óssea, estendendo-se láteroventralmente a esta. A porção parietal da foice projeta-se da metade posterior e se continua com a porção occipital, até unir-se ao tentório ósseo. Esta lâmina se inicia ventralmente à crista sagital, junto à sutura com o frontal. Tanto a foice quanto o teto craniano apresentam sulcos e cristas relacionadas às circunvoluções cerebrais. $\mathrm{Na}$ base da fossa craniana média destaca-se o sulco do quiasma óptico e a sela túrcica. A região pré-esfenoidal apresenta dorsalmente à área do quiasma óptico uma forma em "V" (vértice anterior). Anterior e sob este "V" está o estreito sulco do quiasma, profundamente situado, lateralmente ao qual se situa o forame interno do canal do nervo óptico. Arbitraram-se como limites laterais internos para o basisfenóide os discretos sulcos da artéria carótida interna, desde a fissura esfenoidal até o forame lacerado médio, lateralmente à sela túrcica. $\mathrm{O}$ alisfenóide é côncavo, sendo sobreposto pelo frontal. Na sela túrcica, os processos clinóides anteriores são proeminentes e muito laterais. O tubérculo selar é diminuto, levemente inclinado dorso-ventralmente, sendo lateralmente delimitado pelo sulco do trigêmio e pela borda medial da fissura esfenoidal. A fossa hipofisiária é larga, mas relativamente rasa. $\mathrm{O}$ dorso selar é também relativamente baixo, mas muito inclinado posteriormente. Os processos clinóides posteriores são curtos, mas bem marcados. $\mathrm{Na}$ fossa craniana posterior destacam-se o rochedo (vista cerebral) e a escama mastoidea. A escama mastoidea sutura-se com o esquamosal ao nível do limite pósterodorsal do rochedo pelo qual está sobreposta médioventralmente apresentando-se triangular, com ápice dorsal. Observa-se também um pequeno processo que corresponde ao local de sutura da porção ventral do processo tentório do parietal, que se situa entre a escama mastoidea e o esquamosal. O seio venoso dorsal é profundo e descreve uma trajetória curva (concavidade medial) sobre a parede látero-posterior da cavidade craniana. Mais ventralmente, na borda póstero-lateral do alisfenóide observa-se uma incisura alongada e côncava, que corresponde às margens anterior, medial e pósteromedial do forame lacerado médio. Lateralmente à incisura situa-se a língula esfenoidal, pontiaguda e direcionada póstero-lateralmente; e ainda mais lateralmente a incisura para a tuba auditiva, triangular e com ápice anterior. A margem lateral desta incisura projeta-se posteriormente, penetrando na cavidade timpânica. $\mathrm{O}$ sulco do trigêmio estende-se da fissura esfenoidal ao ápice piramidal do rochedo. No supraoccipital observam-se sulcos e cristas correspondentes aos giros e sulcos encefálicos, bem como os tênues sulcos vasculares meningeus. No supraoccipital está o elemento occipital da foice óssea. É uma lâmina irregular que se estende em direção pósteroventral até o processo tentório, ântero-posteriormente curta, em continuidade a porção parietal da foice. Próximo ao limite com o supraoccipital encontra-se o elemento occipital do processo tentório, de curta extensão ânteroposterior que se estende látero-lateralmente. A forma do elemento occipital do tentório quando observado ventralmente é a de um triângulo de ápice anterior, largo e baixo. No exoccipital observa-se o forame do canal condilóide e a abertura interna do canal do hipoglosso. A abertura anterior do canal condilóide situa-se ventralmente no limite com o basioccipital, a partir de onde um sulco se estende anteriormente. A abertura posterior situa-se na face medial dos côndilos, é grande, ovalada e comumente apresenta-se dividida por septos. Sua abertura interna (médio-posteriormente à sua abertura 
anterior) é pequena e de forma variável. Posteriormente ao dorso selar, o basioccipital apresenta uma superfície marcadamente côncava, correspondendo à depressão da ponte. Posteriormente a esta depressão, e separada dela por uma crista transversal arredondada e irregular, há uma segunda depressão muito mais profunda, relacionada à medula oblonga.

Em A. australis os sulcos e depressões das circunvoluções cerebrais são mais conspícuos, mas os sulcos vasculares menos marcados. O sulco para o seio venoso ventral é mais posterior, e não ventral com relação ao rochedo. O dorso-selar é menos largo proporcionalmente e os processo clinóides posteriores são maiores. Observa-se na base do dorso selar o canal transverso, por onde passa o seio transverso maior da veia jugular externa. No basioccipital as fossas para a ponte e medula oblonga são contínuas e menos profundas.

Mandíbula. O dentário de $O$. byronia é muito robusto (Figs. 11 e 12). No limite anterior do osso está a sínfise mandibular, convexa, mas irregular. Aborda ventral é sinuosa. Anteriormente é marcada pelas rugosidades da porção posterior à sínfise. Posteriormente é côncava até aproximadamente o nível onde se inicia a borda dorsal do ramo. Ainda mais posteriormente é convexa, em função da ondulação do processo angular secundário. O processo alveolar pode ser dividido em "parte incisiva" e "parte molar". A "parte incisiva" está no extremo anterior da borda dorsal. Localiza-se entre a sínfise mandibular (medialmente) e o alvéolo do canino (lateralmente), abrigando os alvéolos para o I/1 e o I/2. O alvéolo do I/1 está em contato com a sínfise mandibular medialmente. Estes alvéolos são oblongos, mas o correspondente ao I/2 é maior e mais profundo que o do I/1. Os septos interalveolares entre os dois incisivos e entre o $\mathrm{I} / 2$ e o $\mathrm{C} / 1$ têm espessura variável. Entre o alvéolo do $\mathrm{C} / 1$ e a série de pós-caninos há um diastema de extensão variável. A "parte molar" engloba os alvéolos para o canino e para os pós-caninos. O alvéolo do $\mathrm{C} / 1$ é muito grande, profundo e ovalado, mas sua margem pode apresentar pequenas irregularidades. Ele é afunilado, anteriormente convexo e inclina-se dorso-anteriormente/ventroposteriormente até o nível do $\mathrm{PC} / 1-2$. Os alvéolos para

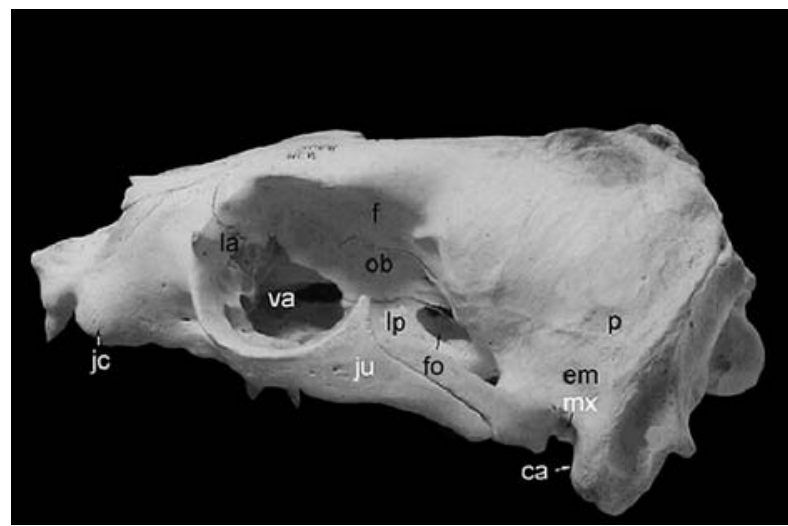

Fig. 9. Arctocephalus australis (Zimmerman, 1783) (MCN 2688), macho adulto. Vista lateral direita do crânio. Barra, $1 \mathrm{~cm}$. (ca, crista mastóide anterior; em, escama mastóide; f, frontal; fo, forame óptico; jc, jugo alveolar do canino; ju, jugal; la, lacrimal; lp, lâmina vertical do palatino; mx, meato acústico externo; p, parietal; va, vacuidade orbital). os /PC desenham uma linha levemente oblíqua; sendo arredondados, profundos e afunilados. O tamanho dos alvéolos é variável, mas usualmente aqueles para o PC1/1 e $\mathrm{PC} / 5$ são menores que os demais. O septo entre os dois primeiros pós-caninos é espesso. Ocasionalmente podem ser observados septos interadiculares extremamente finos e dorsalmente incompletos nos PC/4-5. A face lateral do corpo do dentário é marcamente rugosa, irregular e muito porosa, sendo ligeiramente convexa dorso-ventralmente. $\mathrm{Na}$ porção anterior da face lateral estão os forames mentonianos, grandes, variáveis em número, forma, tamanho e localização (inclusive entre os dentários de um mesmo espécime) (Fig. 11). Podem estar acompanhados de sulcos posteriormente. Na borda ventral observa-se uma proeminência que margeia o limite da sínfise e que pode se estender posteriormente às rugosidades da borda ventral da sínfise. Esta face é perfurada também por uma série de outros forames, diminutos. O processo coronóide é uma larga e alta lâmina óssea (Figs. 11 e 12). Sua borda anterior é retilínea, a dorsal convexa. A borda posterior é irregular e algo inclinada posteriormente, até atingir a bem fechada incisura do dentário. Em sua face medial estão a crista condilóide e outras cristas menores. O processo condilar é muito largo e forte, bastante horizontalizado e maior lateralmente (Fig. 12). Sua superfície articular é levemente côncava látero-medialmente e marcadamente convexa ântero-posteriormente. Esta superfície está pouco acima do nível oclusal. Seu limite lateral é convexo, continuandose por duas cristas condilóides, divergentes, uma mais dorsal que a outra. O processo angular é fortemente inclinado medialmente, baixo e alongado (Figs. 11 e 12). Seu limite posterior é triangular, com forte incisura separando-o do processo condilar. Seu limite anterior é laminar, em ângulo reto e também com marcada incisura separando-o do processo angular secundário. O processo angular é retangular, convexo mais anteriormente e côncavo em seus dois terços posteriores. É separado do forame mandibular por sulco que se estende entre a margem ventral do processo condilar e a margem posterior do processo angular secundário. $\mathrm{Na}$ face lateral do processo angular secundário há uma fossa

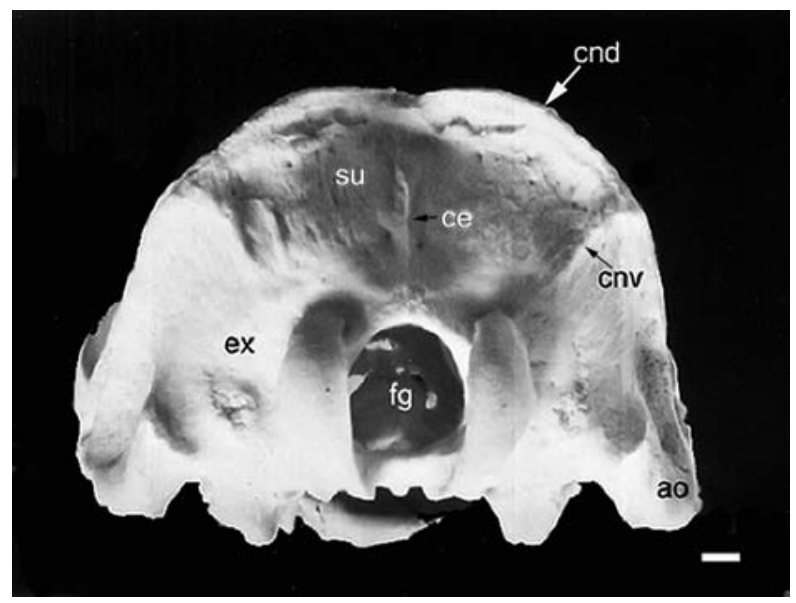

Fig. 10. Arctocephalus australis (Zimmerman, 1783) (MCN 2688), macho adulto. Vista posterior do crânio. Barra, $1 \mathrm{~cm}$. (ao, processo paraoccipital; ce, crista occipital externa; cnd, crista nucal dorsal; cnv, crista nucal ventral; ex, exoccipital; fg, forame magno; su, supraoccipital). 
baixa e alongada. Na face lateral do ramo está a fossa massetérica (Fig. 11), uma área fortemente côncava. Limitase pela crista coronóide (dorsalmente) e pela linha massetérica (ventralmente) que confluem anteriormente. A linha massetérica estende-se posteriormente entre o processo angular e o processo angular secundário, finalizando na extremidade posterior da base destes. Em muitos espécimes observa-se ainda uma segunda concavidade, que margeia "internamente" a fossa massetérica. Dorsalmente sua margem é muito tênue, sobre o processo coronóide; ventralmente seu limite (crista condilóide) também é tênue. A crista condilóide, após margear a fossa massetérica, se estende por curto percurso sobre o processo angular. A sínfise mandibular é romboidal, afilando-se ventralmente e sua superfície é extremamente rugosa. Estende-se desde o limite anterior do dentário até o nível do PC/1 - 3 (Figs. 11 e 12). Posteriormente à sínfise, a face medial do corpo do dentário é ligeiramente convexa dorso-ventralmente e bastante lisa, como também o são a borda medial do processo alveolar e a face do processo angular secundário. Destacase nesta face uma fossa sobre o processo coronóide, o processo angular e o forame mandibular. Esta fossa se estende desde uma crista irregular, convexa anteriormente e posterior à margem anterior do processo coronóide, até o nível do forame mandibular. O forame mandibular é uma

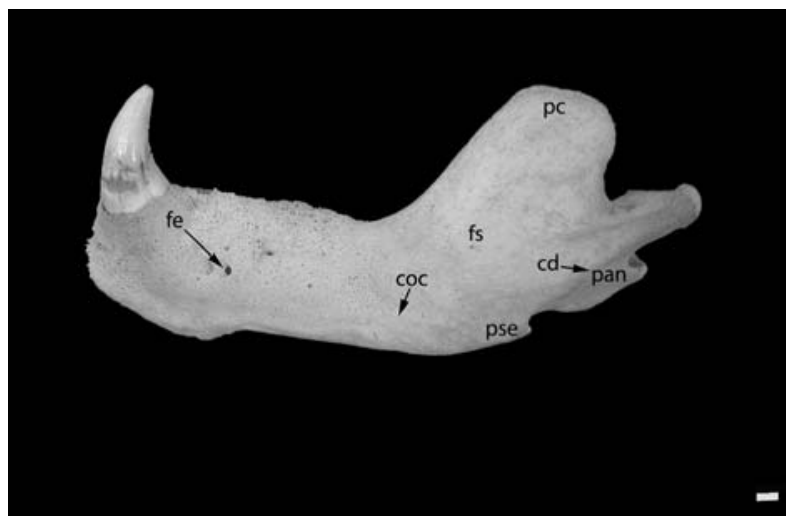

Fig. 11. Otaria byronia (Blainville, 1820) (MCN 2505), macho adulto. Vista lateral do dentário esquerdo. Barra, $1 \mathrm{~cm}(\mathrm{~cd}$, crista condilóide; coc, crista coronóide; fe, forames mentonianos; fs, fossa massetérica; pc, processo coronóide; pan, processo angular; pc, processo coronóide; pse, processo angular secundário).

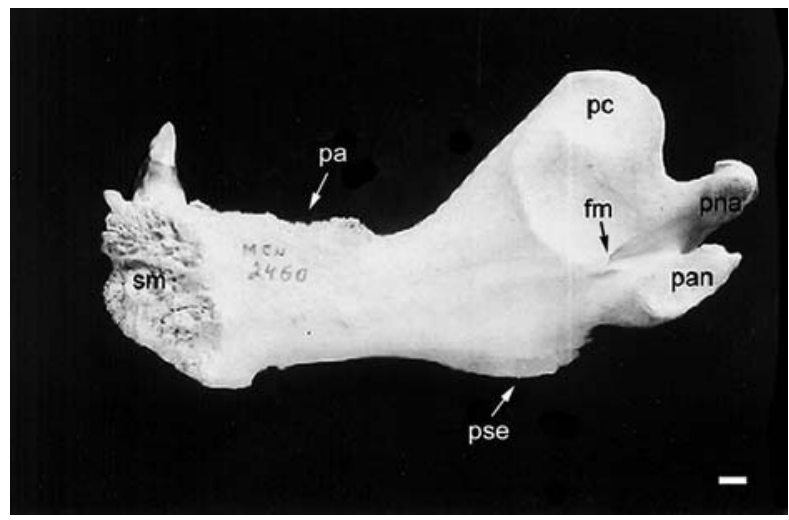

Fig. 12. Otaria byronia (Blainville, 1820) (MCN 2459), macho adulto. Vista medial do dentário direito. Barra, $1 \mathrm{~cm}(\mathrm{fm}$, forame mandibular; pa, processo alveolar; pan, processo angular; pc, processo coronóide; pna, processo condilar; pse, processo angular secundário; sm, sínfise mandibular). abertura/fenda alta e alongada. Situa-se dorsalmente próximo à porção média do processo angular secundário (Fig. 12). Nas fêmeas, o ângulo mandibular é menor, o processo angular secundário pode ser incipiente e a face articular do processo condilar pode ser mais baixa em relação ao plano oclusal.

Em Arctocephalus australis o dentário, de um modo geral, tem um aspecto mais delicado, menos irregular e menos poroso (Figs. 13 e 14). As rugosidades da borda da sínfise mandibular não são visíveis na face lateral do osso. O diastema entre o $\mathrm{C} / 1$ e o $\mathrm{PC} / 1$ é proporcionalmente maior. Os alvéolos para os pós-caninos são mais rasos, menos arredondados e não são afunilados dorsoventralmente. Os septos interalveolares entre os póscaninos são mais conspícuos, especialmente aquele entre os PC/1 e PC/2. Os septos interadiculares são visíveis a partir do $\mathrm{PC} / 2$. No alvéolo do $\mathrm{PC} / 5$ pode haver dois septos interalveolares, indicando a presença de três raízes. A borda ventral é apenas ligeiramente convexa e não é irregular. $\mathrm{O}$ processo angular secundário está em geral ausente, ou é muito incipiente (Figs. 13 e 14). Os forames mentonianos são menores. Ainda que estes também sejam muito variáveis, as aberturas ocorrem sempre entre a borda anterior e o nível do PC/4 aproximadamente. Um forame mentoniano anterior pode ser individualizado, localizandose ventralmente aos incisivos.

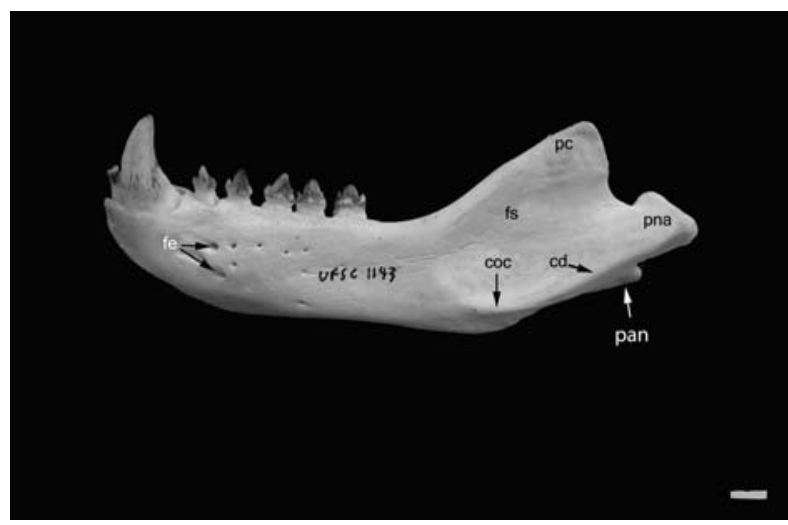

Fig. 13. Arctocephalus australis (Zimmerman, 1783) (UFSC 1131), macho adulto. Vista lateral do dentário esquerdo. Barra, $1 \mathrm{~cm}(\mathrm{~cd}$, crista condilóide; coc, crista coronóide; fe, forames mentonianos: fs, fossa massetérica; pc, processo coronóide; pan, processo angular; pna, processo condilar).

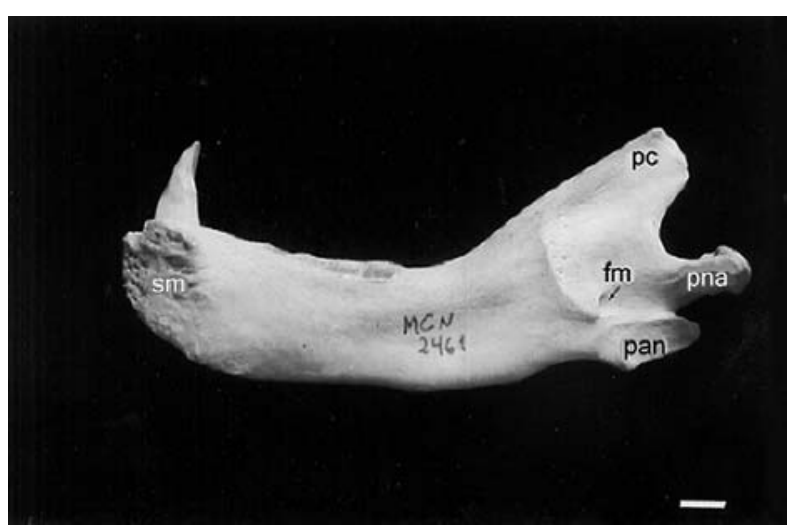

Fig. 14. Arctocephalus australis (Zimmerman, 1783) (MCN 2461), macho adulto. Vista medial do dentário direito. Barra, $1 \mathrm{~cm}(\mathrm{fm}$, forame mandibular; pan, processo angular; pc, processo coronóide; pna, processo condilar; sm, sínfise mandibular). 
A

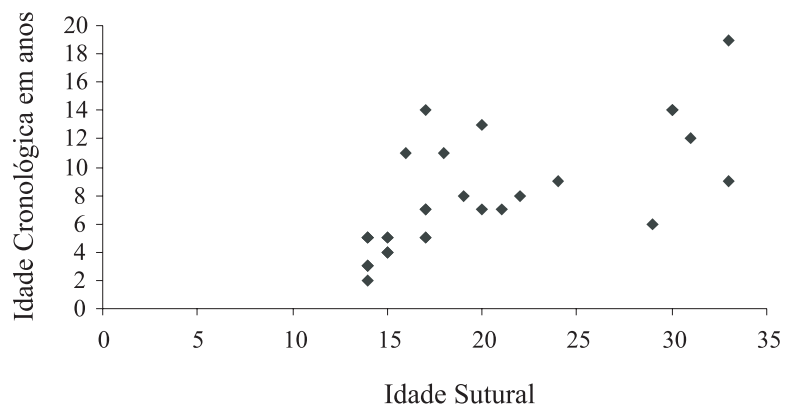

B

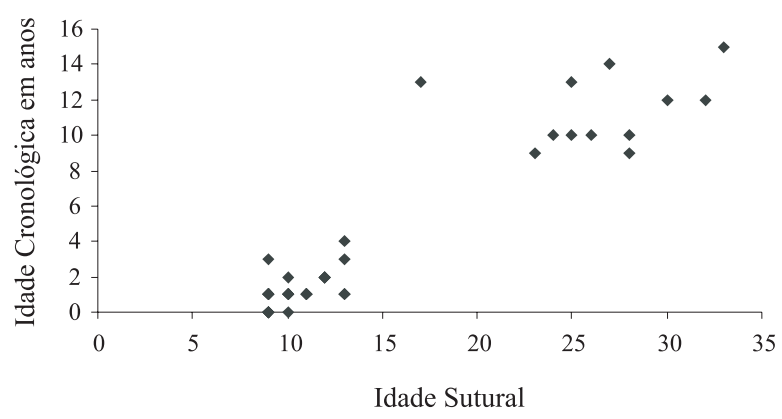

Fig. 15. Relação entre as idades sutural e cronológica. (A, Otaria byronia, n, 21; B, Arctocephalus australis, n, 23).

\section{DISCUSSÃO}

Ainda que Rosas et al. (1993) tenha demonstrado em $O$. byronia a correlação entre as idades sutural e a idade cronológica, em Arctocephalus australis o padrão de crescimento (e, portanto, de fechamento das suturas) é outro, como ficou demonstrado pela diferença das correlações idade sutural x idade absoluta cronológica entre as espécies. Em acréscimo, as diferenças entre as espécies no que concerne às estimativas de faixa etária empregando o método de SimõEs-Lopes et al. (1995) denotam que os machos de $O$. byronia obliteram algumas das suturas cranianas posteriormente com relação ao basicrânio, o que provavelmente está correlacionado com seu maior tamanho craniano.

Outrossim, destacamos que no método de SiverTSEN (1954), são consideradas apenas nove suturas cranianas, e dentro da faixa etária "adulto" encontram-se diferentes graus de fechamento das mesmas. Verificou-se que a sutura pré-esfenóide/basisfenóide pode estar sobreposta pelas apófises vomerianas, o que dificulta sua avaliação. Adicionalmente, parece haver uma valorização excessiva de uma porção muito pequena de determinada sutura (fusionada ou não), o que determina de maneira decisiva a faixa etária do espécime. Por outro lado, esse método não inclui várias suturas que poderiam aprimorar os resultados. Além disso, a extensão do fechamento/ fusionamento de uma sutura pode ainda variar conforme os lados de um mesmo espécime.

Ao contrário do que ocorre com A. australis, indivíduos subadultos de $O$. byronia já apresentam a crista sagital e o processo mastóide bem desenvolvidos. De acordo com TuRner (1848), o tamanho do processo mastóide e do processo paraoccipital estão relacionados intimamente ao tamanho do indivíduo, ao sexo e à idade.
Ressalta-se que (a) os otarídeos (especialmente machos) comumente atingem a maturidade sexual (gonadal) antes de serem osteologicamente adultos e de estarem comportamentalmente aptos para a reprodução; e que (b) as epífises dos ossos longos muitas vezes não estão ainda fusionadas em indivíduos com idade sutural acima de 19. Hamilton (1934) afirma que, quando da maturação sexual, os sexos não apresentam todas as características externas e osteológicas que caracterizam o indivíduo adulto. Tal fato sugere um retardo da maturação somática, principalmente nos machos (relativa aceleração da maturação sexual). Neste contexto, a heterocronia pode ser levantada como fator causal.

As principais distinções entre os crânios de $O$. byronia e A. australis são de natureza alométrica, tais como o tamanho do processo supra-orbital e dos caninos. Otaria byronia aparentemente desenvolve-se mais com relação à $A$. australis, o que pode ser uma questão de modificação de tempo e/ou de taxa ontogenética. O menor tamanho de A. australis é uma característica primitiva para os Otariidae (REPENNING, 1976; BERTA \& WYSS, 1994). Relacionada à alometria, há uma maior verticalização do crânio em $O$. byronia, o que se evidencia na maior participação do frontal na parede medial da órbita, na forma do processo mastóide e na extensão do processo paraoccipital.

Acerca da protuberância pré-maxilar, BERTA \& WYSS (1994) afirmam que, tanto no gênero Arctocephalus como nos Otariinae, ela é proeminente, dorsal e anterior à margem alveolar (estado de caráter $=1$ ). Contudo, no material estudado de $O$. byronia ela não é proeminente (estado de caráter $=0$ ).

BERTA \& DeméRÉ (1986) afirmam que as séries de alvéolos no maxilar são divergentes posteriormente em Arctocephalus e praticamente paralelas em O. byronia. No material avaliado, todavia, isto não foi corroborado dadas as variações encontradas nas séries alveolares das espécies enfocadas.

De acordo com BERTA \& Wyss (1994), a ausência de uma fossa naso-labialis para o músculo quadrado (lábio superior) é uma característica que agrupa todos os Pinnipedia e que teria sofrido uma reversão em Pinnarctidion Barnes, 1979. Não obstante, essa fossa pode ser freqüentemente observada tanto em $O$. byronia quanto em A. australis.

Ainda quanto ao maxilar, pode-se destacar que ele participa dos limites dos forames incisivos mesmo em adultos de $O$. byronia, o que se verifica unicamente em juvenis de A. australis. Outra característica que indica juvenilização são os septos inter-alveolares muito finos, característica esta que também se observa no dentário.

BERTA \& RAY (1990) referem-se a uma pequena porção do processo palatino do maxilar que se estende posteriormente ao processo alveolar. O fato de tal extensão posterior ser menor em A. australis pode refletir um estágio mais primitivo. Nos crânios de Phocartos hookeri (Gray, 1844) e Neophoca cinerea (Peron, 1816) figurados por KING (1960), observa-se que esta extensão não é conspícua em $P$. hookeri, mas o é em $N$. cinerea. Não foi possível comprovar a presença da abertura proximal do canal lacrimal. BERTA $(1991,1994)$ e BERTA \& Wyss (1994) descrevem uma fossa muscular sobre o 
lacrimal (músculo oblíquo inferior do olho). É provável que o forame observado na face externa do lacrimal das espécies aqui estudadas corresponda a essa fossa, que também está presente em outros carnívoros arctóideos. Entretanto, BERTA (1991) afirma que essa estrutura está ausente em Pinnipedia. Todavia, pelo pequeno número de espécimes onde o lacrimal pôde ser individualizado, é necessário material adicional. $\mathrm{O}$ esclarecimento dessa questão é relevante, uma vez que a perda/redução do canal lacrimal é interpretada como uma adaptação ao meio aquático, devendo-se levar em conta, porém, que os otarídeos permanecem em terra um tempo bastante longo.

Sobre o jugal é interessante a diferença entre as espécies estudadas no que concerne à sutura com o processo zigomático do temporal. BERTA \& WYSS (1994) atribuem o mesmo estado de caráter (estado de caráter $=0$ ) quanto à forma da articulação do jugal com processo zigomático do temporal, tanto para o gênero Arctocephalus quanto para os Otariinae. Entretanto, observa-se que em Arctocephalus australis essa articulação é do tipo "splintlike" (estado de caráter $=0$ ), ao passo que em $O$. byronia é do tipo "mortised" (estado de caráter 1). Esse aspecto de $O$. byronia é semelhante ao ilustrado por KING (1960) para $N$. cinerea e está intimamente associado ao desenvolvimento do processo pós-orbital. Por conseguinte, o estado desse caráter nos Otariinae precisa ser revisado.

O palatino de $O$. byronia é bastante simplificado comparativamente aos Fissipedia. A presença da sutura entre o frontal e o palatino reflete o padrão geral dos mamíferos. O mesmo não ocorre em muitos pinipédios, essencialmente devido à presença da vacuidade orbital, uma sinapomorfia de Pinnipedimorpha (BERTA, 1991).

MurIE (1874) afirma que o vômer não chega a contatar o palatino em $O$. byronia. Contudo, neste estudo observou-se que esse contato é relativamente freqüente nessa espécie.

No frontal, características de $O$. byronia como a ausência de processo maxilar exposto externamente e cristas frontais externas bem delimitadas são observadas mais comumente nos juvenis de A. australis.

REPEnNing \& TEDFord (1977) e BERTA \& DeméRÉ (1986) afirmam que a sutura fronto-parietal situada posteriormente, na porção craniana propriamente dita, é uma sinapomorfia de Thalassoleon Repenning \& Tedford, 1977. Essa sutura, porém, situa-se igualmente nessa posição em $O$. byronia.

Cabe mencionar que Mitchell (1968) afirma que o tentório ósseo não contata a fossa cerebelar dos Otariidae, o que está em desacordo com o que foi observado no presente trabalho.

A presença mais freqüente das aberturas do canal vidiano em $O$. byronia pode ser também interpretada como um caráter juvenilizado, na medida em que se pode observá-las em diversos juvenis de A. australis (ao passo que nos adultos elas se encontram obliteradas).

Mitchell (1968) descreve diversos caráteres para Imagotaria dowsi Mitchell, 1968 (região auditiva) que se mostraram altamente variáveis, como por exemplo, as projeções ventrais do ectotimpânico e o pequeno processo ventral ao meato acústico externo. Ainda que KING (1960) já tenha se referido à alta variabilidade no relevo dos timpânicos, esse relevo é utilizado por BERTA \& DEMÉRÉ (1986) para a análise das relações genealógicas dos otarídeos. Estes últimos afirmam que uma projeção alongada e póstero-ventral na parede da bula timpânica é uma característica de Otariinae. Aqui, contudo, tais projeções foram também observadas em $A$. australis.

DREHMER \& RIBEIRO (1998) afirmam que o assoalho do meato acústico externo apresenta dimorfismo sexual. Entretanto, o assoalho proeminente que esses autores descrevem como característico de machos pôde também ser visualizado em fêmeas adultas.

No que concerne ao entotimpânico, sua forma nas espécies aqui enfocadas está em quase total conformidade com o padrão descrito para a família por TEDFORD (1976), salvo quanto à sua extensão. Aquele autor afirma que o entotimpânico não ultrapassa o pétreo, o que foi aqui falseado.

BERTA \& Wyss (1994) consideram que o pétreo visível através do forame lacerado posterior é uma sinapomorfia de Odobenus Linnaeus, 1758, Pinnarctidion, Desmatophoca Condon, 1906, Allodesmus Mitchell, 1975 e Phocidae. Entretanto, pode-se observar o pétreo de $O$. byronia através de tal forame.

No basioccipital, tanto $O$. byronia quanto $A$. tropicalis apresentam as fossas e os tubérculos dessa região muito semelhantes e mais desenvolvidos do que em A. australis, sendo que o tubérculo faríngeo pode apresentar-se como uma crista que divide as fossas faríngeas, como foi observado por DREHMER \& FERIGOLO (1997) para A. tropicalis. Um processo condilar elevado acima do nível da série alveolar dos pós-caninos inferiores é considerado por BERTA \& Wyss (1994) como uma sinapomorfia de Desmatophoca, Piscophoca e Acrophoca Muizon, 1981. Contudo, se compararmos os exemplares de $O$. byronia com aqueles figurados por BARnes (1972) para Desmatophoca, não se observa qualquer diferença.

MurIe (1874) afirma que o canal da carótida localizase no pétreo, o que está em desacordo com o que foi observado neste trabalho (canal no entotimpânico). TEDFORD (1976) refere que o pétreo participando do canal para a artéria carótida interna, assim como a posição posterior da abertura do canal, são características dos Otarioidea compartilhadas com outros arctóideos. Paradoxalmente, neste estudo constatou-se que, em geral, o canal da carótida é formado apenas pelo entotimpânico. A presença eventual de uma pequena apófise do pétreo nesse canal parece estar associada a uma ossificação incompleta do entotimpânico.

As fêmeas de $O$. byronia maturam mais rapidamente e crescem por menos tempo que os machos (Rosas, 1993). Essa característica possivelmente está relacionada à sua juvenilização, com a presença de determinados caráteres observados apenas em machos imaturos (e. g. vacuidade entre a lâmina vertical do palatino e o pterigóide). A órbita das fêmeas de $O$. byronia é proporcionalmente maior que nos machos, também em função do menor desenvolvimento de cristas e processos, que acentuam as menores dimensões do crânio como um todo.

HAMILTON (1934) refere à constituição mais delicada do crânio das fêmeas, definindo-as como "pup-like head", o que denota seu aspecto pedomórfico com relação 
aos machos. Todavia, maiores estudos são necessários, porque características dos machos, como o desenvolvimento de cristas, tubérculos e processos, e a ausência da vacuidade entre a lâmina vertical do palatino, poderiam ser interpretadas como hipermórficas.

MuRIE (1874) traça alguns comentários acerca da grande diferença entre os sexos no crânio de $O$. byronia, citando trabalhos prévios que também abordaram esse tema. As características descritas por aquele autor foram aqui corroboradas, com duas exceções: (a) não ficou evidente uma maior distinção entre o canal da carótida e o forame lacerado posterior nas fêmeas e (b) a coroa bífida, referida por aquele autor para os dois primeiros incisivos, ocorrem igualmente nos machos.

Diversos trabalhos puseram em xeque a validade das subfamílias de Otariidae os quais consideraram Otariinae e "Arctocephalinae" como convenções sem validade sistemática (e. g. REPENNING \& TEDFORD, 1977; Brunner, 2004). Outrossim, Berta \& Wyss (1994) apresentam um clado que engloba Callorhinus, Arctocephalus e os Otariinae, e outro, menos inclusivo, que engloba os dois últimos.

Segundo BerTa \& Wyss (1994), os Otariinae são caracterizados por dois caráteres de distribuição ambígua, possíveis convergências. O primeiro é um I3/ com secção transversal circular (o que também ocorre em Odobenidae) e o segundo, referem-se à pelagem.

Um estudo comparativo da osteologia dos demais otarídeos certamente iria acrescentar muito a essa problemática e à revisão dos caracteres considerados. A alta variabilidade observada no material estudado, que, mesmo assim, refuta muitas vezes diversos estados de caráter empregados nas análises filogenéticas, reflete claramente a necessidade de um estudo comparativo mais aprofundado da anatomia das espécies recentes de pinipédios.

Agradecimentos. Aos consultores anônimos que revisaram a primeira versão do manuscrito, à Fundação Zoobotânica do Rio Grande do Sul e ao Curso de Pós-graduação em Geociências/UFRGS pelo apoio logístico, aos colegas Patrícia Braun, César Jaeger Drehmer, Marília Aguiar e Ana Maria Ribeiro, ao LAMAq/UFSC e Museu de Zoologia da Unisinos pelo acesso as respectivas coleções científicas, ao Luciano Maciel e ao fotógrafo Eduardo Quadros pela colaboração com as fotografias e a CAPES pela bolsa de pós-graduação concedida à primeira autora.

\section{REFERÊNCIAS BIBLIOGRÁFICAS}

Barnes, L. G. 1972. Miocene Desmatophocinae (Mammalia: Otariidae) from California. Publications in Geological Sciences 89:1-68.

Berta, A. 1991. New Enaliarctos (Pinnipediomorpha) from the Oligocene and Miocene of Oregon and the role of "Enaliarctids" in pinniped phylogeny. Smithsonian Contributions to Paleobiology 69:1-33.

1994. New specimens of the Pinnipedform Pteronarctos from the Miocene of Oregon. Smithsonian Contributions to Paleobiology 78:1-30
Berta, A. \& Deméré, T. A. 1986. Callorhinus gilmorei n. sp. (Carnivora: Otariidae) from the San Diego Formation (Blancan) and its implications for otariid phylogeny. Transactions of the San Diego Society of Natural History 21(7): 111-126.

Berta, A. \& RAY, C. E. 1990. Skeletal morphology and locomotor capabilities of the archaic pinniped Enaliarctos mealsi. Journal of Vertebrate Paleontology 10:141-157.

Berta, A. \& Wyss, A. 1994. Pinniped Phylogeny. In: Berta, A. \& Deméré, T. A. (eds.). Contributions in marine mammal paleontology honoring Frank C. Whitmore, Jr. Proceedings of San Diego Society of Natural History 29:33-56.

Berta, A., Sumich, J. L. \& Kovacs, K. M. 2006. Marine Mammals - Evolutionary Biology. 2nd, San Diego, Academic. 547p. + $16 \mathrm{pl}$.

BrunNer, S. 2004. Fur seals and sea lions (Otariidae): identification of species and taxonomic review. Systematics and Biodiversity 1(3):339-439.

Drehmer, C. J. \& Ferigolo, J. 1997. Osteologia craniana comparada entre Arctocephalus australis e Arctocephalus tropicalis (Pinnipedia, Otariidae). Iheringia, Série Zoologia 81:63-74.

Drehmer, C. J. \& Ribeiro, A. M. 1998. A left temporal bone of an Otariidae (Mammalia, Pinnipedia) from the late Pleistocene of Rio Grande do Sul State, Brazil. Revista da Universidade de Guarulhos 8(6):39-44.

Hamilton, J. E. 1934. The southern sea lion Otaria byronia (de Blainville). Discovery Reports 8:269-318.

King, J. E. 1960. Sea-lions of the Genera Neophoca and Phocartos. Mammalia 24(3):445-456.

Laws, R. M. 1962. Age determination of Pinnipeds with special reference to growth layers in the teeth. Zeitschrift für Säugtierkunde 27(3):129-146.

Mitchell, E. D. 1968. The Mio-Pliocene Pinniped Imagotaria. Journal Fisheries Research Board of Canada 25(9): 1843-1968.

Murie, J. 1874. Researches upon the anatomy of the Pinnipedia. Part III. Descriptive anatomy of the sea lion (Otaria jubata). Transactions of the Zoological Society 8:501-582.

Repenning, C. A. 1976. Adaptive evolution of sea lions and walruses. Systematic Zoology 25(4):375-390.

Repenning, C. A. \& Tedford, R. H. 1977. Otarioid Seals of Neogene. U. S. Geological Survey Professional Paper 992:1-93.

Rosas, F. C. W., Pinedo, M. C.; Marmontel, M. \& Haimovici, M. 1994. Seasonal movements of the south american sea lion (Otaria flavescens, Shaw) of the Rio Grande do Sul coast, Brazil. Mammalia 58(1):51-59.

Rosas, F. C. W.; Haimovici \& Pinedo, M. C. 1993. Age and growth of the south american sea lion, Otaria flavescens (Shaw, 1800), in Southern Brazil. Journal of Mammalogy 74(1): 141-147.

Schiavini, A. C.; Lima, M. M.; Batallés, L. M. 1992. Growth structures of maxillary canines of the southern fur seal (Arctocephalus australis). Marine Mammals Science 8(1):89-93

Simões-Lopes, P. C.; Drehmer, C. J. \& Ott, P. H. 1995. Nota sobre os Otariidae e Phocidae (Mammalia: Carnivora) da costa norte do Rio Grande do Sul e Santa Catarina, Brasil. Biociências 3(1):173-181.

SivERTSEN, E. 1954. A survey of the eared seals (family Otariidae) with remarks on the Antarctic seals colected by $M / K$ "Norvegia" in 1928-1929. Det Norske VidenskapsAkademii 36:1-76.

TEDFORD, R. H. 1976. Relationship of pinnipeds to other carnivores (Mammalia). Systematic Zoology 25(4):363-374.

TuRNER, H. N. 1848. Observations relating to some of the foramina at the base of the skull in Mammalia, and on the classification of the Order Carnivora. Proceedings of the Zoological Society 16:63-87.

Recebido em junho de 2006. Aceito em julho de 2007. ISSN 0073-4721

Artigo disponível em: www.scielo.br/isz 